\title{
Pepper and Garlic Extracts as an Alternative Treatment to Onychomycosis: AMyth or Truth?
}

\author{
Hsuan-Hsiang Chen* \\ Department of Dermatology, National Taiwan University Hospital and National Taiwan University College of Medicine, Taipei, \\ TaiwanMiami, Miller School of Medicine, Miami, FL, USA.
}

\begin{abstract}
Received: May 25, 2021; Accepted: May 29, 2021; Published: June 01, 2021
*Corresponding author: Hsuan-Hsiang Chen, MD,Department of Dermatology, National Taiwan University Hospital, 7, Chung-Shan South Road,Taipei, Taiwan, Tel. No: +886-2-2356-2141; Fax. No: +886-2-2393-4177, E-mail: beauty101@gmail.com
\end{abstract}

Onychomycosis is a chronic disease ofa nail infection by the fungi. Based on the mode of nail invasion and morphologic patterns, it can be divided into 5subtypes: distal and lateral subungualonychomycosis, proximal subungualonychomycosis, superficial onychomycosis, total dystrophic onychomycosis, and endonyxsubungualonychomycosis.Common pathogens are dermatophytes, non-dermatophyte molds, and yeasts. In recent years, the development of new antifungal agents, such as allylamines and azoles, has provided good treatment options for onychomycosistherapy.

There is a growing interest in the use of plant-derived compounds or alternatives to treat dermatophyte infection. Recently, a Chinese web page describing an alternative method for onychomycosis by using garlic and pepper extractswas very popular [Figure 1] [1]. They described 200 cases of onychomycosis patients treated once daily with a mixture of $100 \mathrm{~g}$ garlic and $20 \mathrm{~g}$ pepper extracted with $500 \mathrm{ml}$ acetic acid for 30 days. They claimed the cure rate was $94.05 \%$ and the effective rate was $99.88 \%$. Although it may seem effective, the detailed exact preparation methods, the culture results, and the subtypes of the onychomycosis were not described. The treatment responses also seemed too good to be true. Martin et al. reviewed 7 controlled clinical trials performed to determine the effectiveness of plant extracts against fungal infection [2]. Among them, tea tree oil was the most thoroughly clinically tested. Solanum species and oil of bitter orange preparations were also reviewed. However, there were no researches on garlic or pepper preparation. Till now, there are still no peer-reviewed, double-blind, placebo-controlledclinical trials of garlic or pepper-based preparations used as an alternative treatment method for onychomycosis.

Garlic (Allium sativum) is one of the most cultivated plants used as a spice. It is also widely used for its therapeutic properties, including antifungal effects. Allium plants contain active compounds such as alliin, allicin, ajoene, sterols, flavonoids, and phenolic acids [3]. Allicin is one of the most important compounds from Allium species known to exhibit antioxidant as well as anti-bacterial, anti-viral, anti-parasitic, and fungicidal activity against many fungal species [4]. This A. sativum extract canresult in irreversible ultrastructural changes and loss of structural integrity in fungal cells [5]. It also affected the germinationcapacity. In vivo, the antioxidant activityof A. sativum extract may be effective as a local or systemic anti-inflammatory therapy and target the oxidative stress from the inflammation associated with onychomycosis.

The A.sativumextractiseffectiveagainstMeyerozymaguilliermondii and Rhodotorulamucilaginosa cultured from the toenails of a patient with onychomycosis[5]. Parvu et al. demonstrated the antifungal effect of $4 \%$ garlic extract was comparable to naftifine. Venugopal et al. also investigated the anti-dermatophyte activity of the aqueous extract of $A$. sativum against 88 clinical isolates of dermatophytes[6]. The aqueous extract of garlic with a dilution of 1:150 and 1:100 inhibited $50 \%$ and $90 \%$ of the various fungal isolates, respectively. The inhibitory results were comparable to ketoconazole 1 and $2.5 \mathrm{ug} / \mathrm{mL}$.Amer et al. used topical application of the aqueous garlic extractcontaining allicin $(13.03 \mathrm{mg} / \mathrm{ml})$ twice daily for one week to treat dermatophytefungal infection in guinea pigs and rabbits. They showed complete healing in 14 to 17 days. The inhibitory concentration of allicin for dermatophyteranged from 130 to $200 \mathrm{mg} / \mathrm{l}$ [7]. However, there is no report of in vivo clinical application of allicin or A. sativum extract for the treatment of cutaneous fungal infection on human subjects.

As for pepper extract, the saponin(CAY-1) from cayenne pepper (Capsicum frutescens) was also found to have fungicidal effects against Candida albicans and Aspergillus species [8]. CAY-1 can also enhance the antifungal activity of amphotericin B and itraconazole against Candida and Aspergillus [8,9].Stergiopoulou et al. found more than $90 \%$ of hyphal metabolic activity was inhibited by CAY-1 under the concentration of 10 to $20 \mu \mathrm{g} / \mathrm{ml}[10]$. However, in vivoantifungal activity against human dermatophyte infection or onychomycosis is still lacking.

In conclusion, there is still no in vivo clinical study to evaluate the therapeutic effects of garlic or pepper extracts foronychomycosis. The combination of garlic and pepper extracts may be synergistic but further in vivostudies remain mandatory to prove this concept. 


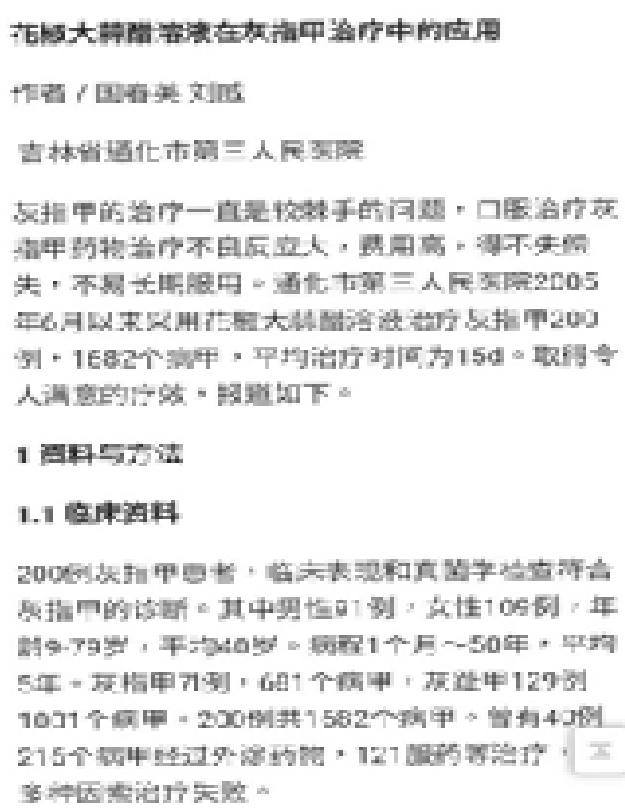

\section{2 ants 法}

(1)

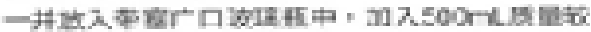

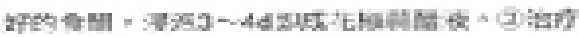

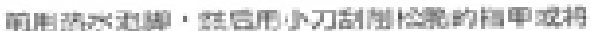

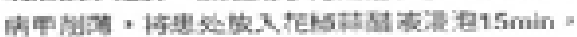

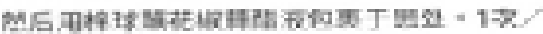

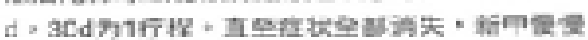
长出

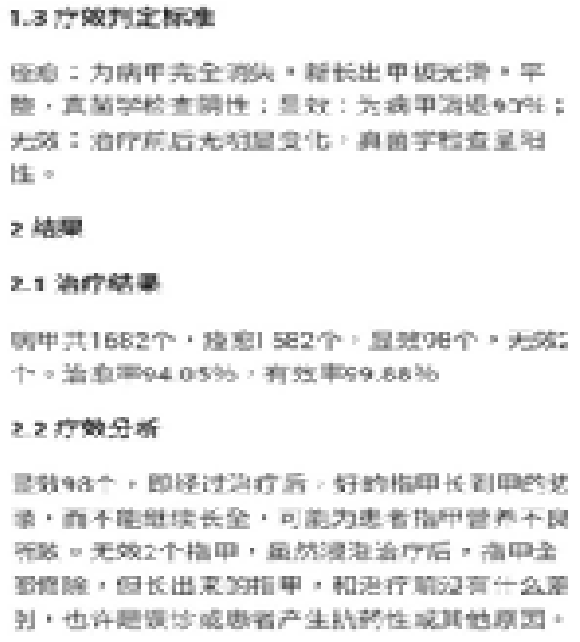

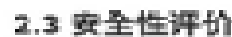

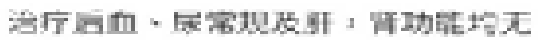

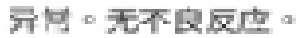

\section{4 店本preter}

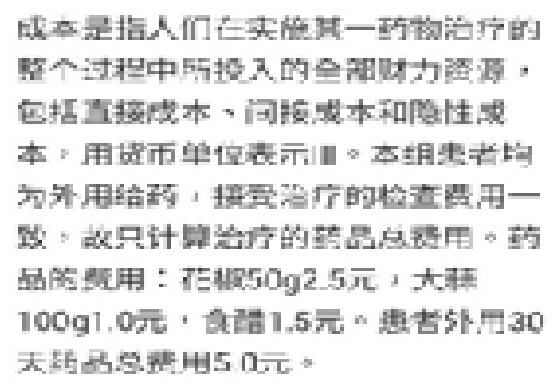

Fig 1: A Chinese web page describing an alternative method for onychomycosis by using garlic and pepper extracted with acetic acid.

\section{References}

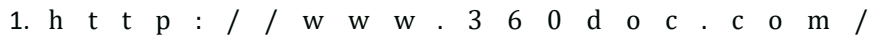
content/19/0607/01/1558965_840886590.shtml.

2. Martin KW, Ernst E. Herbal medicines for treatment of fungal infections: a systematic review of controlled clinical trials. Mycoses. 2004;47:87-92. doi: 10.1046/j.1439-0507.2003.00951.x.

3. Vlase L, Parvu M, Parvu E, Toiu A. Chemical constituents of three Allium species from Romania. Molecules. 2013;18:114-127. doi: 10.3390/molecules18010114.

4. Martins N, Barros L, Henriques M, Silva S, Ferreira ICFR. Activity of phenolic compounds from plant origin against Candida species. Ind Crop Prod. 2015;74:648-670.

5. Pârvu M, Mot CA, Pârvu AE, Mircea C, Stoeber L, Rosca-Casian O, et al. Allium sativum Extract Chemical Composition,Antioxidant Activity and Antifungal Effect against Meyerozyma guilliermondii and Rhodotorula mucilaginosa Causing Onychomycosis. Molecules. 2019;24:3958. doi:10.3390/molecules24213958.
6. Venugopal PV, Venugopal TV. Antidermatophytic activity of garlic (Allium sativum) in vitro. Int J Dermatol. 1995;34(4):278-279. doi: 10.1111/j.1365-4362.1995.tb01597.x.

7. Amer $M$, Taha $M$, Tosson $Z$. The effect of aqueous garlic extract on the growth of dermatophytes Int J Dermatol. 1980;19(5):285-287. doi: 10.1111/j.1365-4362.1980.tb00331.x.

8. De Lucca AJ, Bland JM, Boue S, Vigo CB, Cleveland TE, Walsh TJ. Synergism of CAY-1 with amphotericin B and itraconazole. Chemotherapy. 2006;52:285-287. doi: 10.1159/000095959.

9. Renault S, De Lucca AJ, Boue S, Bland JM, Vigo CB, Selitrennikoff CP. CAY-1, a novel antifungal compound from cayenne pepper. Med Mycol. 2003;41:75-81. doi: 10.1080/mmy.41.1.75.82.

10. Stergiopoulou T, De Lucca AJ, Meletiadis J, Sein T, Boue SM, Schaufele R. In vitro activity of CAY-1, a saponin from Capsicum frutescens, against Microsporum and Trichophyton species. Med Mycol. 2008;46(8):805810. doi:10.1080/13693780802089831. 